\title{
Experimental survey of temperature, time and cross-linking agent effects on polydimethylsiloxane composite membranes performances in sulfur removal
}

\author{
Mohsen Farsi $^{1} \cdot$ Bizhan Honarvar $^{2} \cdot$ Amir Heydarinasab $^{1} \cdot$ Mehdi Arjmand $^{1}$
}

Received: 25 September 2017 / Accepted: 2 June 2018 / Published online: 6 June 2018

(c) The Author(s) 2018

\begin{abstract}
Four types of the multi composite membranes were fabricated to decrease the sulfur content in diesel fuel, which the investigated polymers are polydimethylsiloxane (PDMS), polyethyleneglycol (PEG), polyethersulfonic (PES) and cross-linked polyacrylonitrile (PAN) with tetra-ethyl-ortho-silicate (TEOS). The effects of the operating parameters such as the crosslinking temperature $\left(65-85^{\circ} \mathrm{C}\right)$ and cross-linking time $(0.5-2.5 \mathrm{~h})$ were studied on the membranes performances. The results showed that the sulfur selectivity of PDMS/PEG/PES/PAN membranes were improved through increasing temperature and time. In addition, most of the total flux and the lowest amount of sulfur in the back flow is related to composite membranes of PEG + PDMS.
\end{abstract}

Keywords Composite membrane $\cdot$ Sulfur content removal $\cdot$ Cross-linking agent $\cdot$ PDMS $\cdot$ PEG $\cdot$ PAN

\section{Introduction}

The used membrane materials for removing sulfur are mostly including hydrophobic membranes such as polyurethane, polyurea/polyurethane, polyamide, natural rubber, polystyrene-butadiene and polydimethylsiloxane. Hydrophilic properties of the membranes clearly increase the selectivity to the sulfur compounds which usually are more polar than hydrocarbons. The most common methods for making membranes with high selectivity and flux include cross-linking, blending, filling and copolymerization. Lin et al. studied the solubility of gasoline blending in polyethylene glycol [1]. They concluded that sulfur recovery rate by increasing the amount of cross-linking agent and the cross-linking time increases. Lin et al. used polyethylene glycol and polyurethane polymers for fluidized bed catalytic cracking unit gasoline desulfurization [2]. Wu et al. improved the stability of the interface between the active

Amir Heydarinasab

amir.heydarinasab@hotmail.com

1 Department of Chemical Engineering, Science and Research Branch, Islamic Azad University, Tehran, Iran

2 Department of Chemical Engineering, Marvdasht Branch, Islamic Azad University, Marvdasht, Iran layer of polydimethylsiloxane and base layer of polyethersulfone by the aminosilane and amino propyl trimethoxysilane [3]. Their results showed that with increase of cross-linking agent penetration flux is uniformly reduced. The effect of tetraethyl ortho silicate on the increasing selectivity in the Polydimethylsiloxane membrane has been studied by $\mathrm{Xu}$ et al. [4]. In another study, manufacturing of polydimethylsiloxane and polyamide composite membrane in separation of heptane from thiophene was studied [5]. The transport properties of gases in polydimethylsiloxane (PDMS)/zeolite a mixed matrix membranes (MMMs) were determined based on pure gas permeation experiments in study of Rezakazemi et al. 2012. The permeation rates of $\mathrm{C}_{3} \mathrm{H}_{8}, \mathrm{CH}_{4}, \mathrm{CO}_{2}$, and $\mathrm{H}_{2}$ were evaluated through a dense homogeneous pure PDMS membrane and PDMS/4A MMMs to assess the viability of these membranes for natural gas sweetening and hydrogen purification. SEM investigations showed good adhesion of the polymer to the zeolite in MMMs. Permeation performance of the membranes was also investigated using a laboratory-scale gas separation apparatus and effects of feed pressure, zeolite loading and pore size of zeolite on the gas separation performance of the MMMs were evaluated [6]. Rezakazemi et al. cross-linked polydimethylsiloxane (PDMS) membranes supported on cellulose acetate (CA) and polyamide (PA) microfiltration membranes were prepared by pre-wetting technique for pervaporation (PV) 
dehydration of ethanol. The experiments were carried out to investigate the effects of support layer and permselective thickness on the separation performance of membranes at different operating conditions particularly initial ethanol concentrations and temperatures. The results revealed that increasing feed concentration and temperature increases total permeation flux. PDMS/PA membrane showed better overall performance than PDMS/CA membrane [7]. Chen et al. investigated cross-linked polydimethylsiloxane (PDMS)-polyetherimide (PEI) composite membranes preparation, in which asymmetric microporous PEI membrane prepared with phase inversion method acted as the microporous supporting layer in the flat-plate composite membrane. Membrane characterization was conducted by Fourier-transform infrared and scanning electronic microscopy analysis. The composite membranes were employed in pervaporation separation of n-heptane-thiophene mixtures. Effect of amount of PDMS, cross-linking temperature, amount of cross-linking agent, and cross-linking time on the separation efficiency of $n$-heptane-thiophene mixtures was investigated experimentally [8].

Rostamizadeh et al. investigated Gas permeability through synthesized polydimethylsiloxane (PDMS)/zeolite 4A mixed matrix membranes (MMMs) with the aid of artificial neural network (ANN) approach. Kinetic diameter and critical temperature of permeating components (e.g., $\mathrm{H}_{2}, \mathrm{CH}_{4}, \mathrm{CO}_{2}$ and $\mathrm{C}_{3} \mathrm{H}_{8}$ ), zeolite content and upstream pressure as input variables and gas permeability as output were inspected. Collected data of the experimental operation was used to ANN training and optimum numbers of hidden layers and neurons were obtained by trial-error method. As a result, ANN can be recommended for the modeling of gas transport through MMMs [9].

Rezakazemi and Mohammadi developed robust artificial neural network (ANN) to forecast sorption of gases in membranes that comprised porous nanoparticles dispersed homogenously within polymer matrix. The main purpose of this study was to predict sorption of light gases $\left(\mathrm{H}_{2}, \mathrm{CH}_{4}\right.$, $\mathrm{CO}_{2}$ ) within mixed matrix membranes (MMMs) as function of critical temperature, nanoparticles loading and upstream pressure. The prediction results were remarkably agreed with the experimental data with MSE of 0.00005 and correlation coefficient of 0.9994 [10].

In other work of Rezakazemi et al., a facile strategy for the synthesis of binary fillers nanocomposite membranes containing fumed silica (FS) and octatrimethylsiloxy polyhedral oligomeric silsesquioxane (POSS) nanoparticles was proposed to prepare high-performance PDMS-FS-POSS nanocomposite membranes. To fully explore the synergistic effect between POSS and FS nanoparticles, thermal stability by thermo-gravimetric analysis (TGA) and dispersion quality by scanning electron microscopy (SEM) were investigated, while the crosslinked network was studied by
Fourier-transformed infrared spectroscopy (FTIR). The results showed that the thermal stability of these novel nanocomposite membranes was much better than that of the neat membrane thermodynamically, dipole-dipole interaction between the functional groups is the main parameter leading to better dispersion and thermal stability [11]. Furthermore, it was found that the separation properties of different gases $\left(\mathrm{H}_{2}, \mathrm{C}_{3} \mathrm{H}_{8}, \mathrm{CO}_{2}\right.$ and $\left.\mathrm{CH}_{4}\right)$ across the nanocomposite membranes were enhanced with increasing FS content. All the improvements observed can be attributed to synergistic interactions between FS and POSS [12]. Rajesha et al. synthesized oxide-zeolite composite membranes for benzophenone-3 removal from water. They concluded that membrane performances were significantly improved after the addition of $\mathrm{ZnO}-$ zeolite in the cellulose acetate solution [13]. Ghasemian et al. used polyvinylidene fluoride (PVDF) and nano-porous silica particle. Their results show that PVDF/ $\mathrm{SiO}_{2}$ nano-composite membranes exhibited enhanced antifouling property compared to neat PVDF membrane [14]. $\mathrm{Xu}$ et al. manufactured a gradient cost-efficient composite membrane. They concluded that when the additive amount of OMWCNTs was $1 \mathrm{wt} \%$, the composite membranes presented an excellent flux [15].

In this study, the total sulfur in diesel product of an oil refinery was reduced from $6380 \mathrm{ppm}$ to $1700 \mathrm{ppm}$ using composite membranes of PDMS, PDMS + PEG, PDMS + PES and PDMS + PAN, as well as the cross-linking technique by TEOS in a module of flat sheet membranes. The effect of operational variables such as cross-linking temperature and cross-linking time on the total flux of the stream and total sulfur in the retentate stream was evaluated.

\section{Materials and methods}

\section{Materials}

To manufacture the composite membranes, the following laboratory material were used:

1. Tetraethyl ortho-silicate (TEOS) with an average molecular weight of approximately $208 \mathrm{~g} / \mathrm{mol}$ (Merk, Germany).

2. Oligomers of Polydimethylsiloxane (PDMS) with an average molecular weight of approximately $40,000 \mathrm{~g} /$ mol and viscosity $5000 \mathrm{MPa}$ s (Aldrich, USA).

3. Polyethylene glycol (PEG) with an average molecular weight of approximately $4000 \mathrm{~g} / \mathrm{mol}$ (BASF, Germany).

4. Polyethersulfone (PES) with an average molecular weight of about 58,000 g/mol (flakes, BASF, Germany). 
5. Polyacrylonitrile (PAN) with an average molecular weight of about 45,000 g/mol (Merk, Germany).

6. Polyvinylpyrrolidone (PVP) k90 as a filler with an average molecular weight of approximately $360,000 \mathrm{~g} /$ mol (Merk, Germany).

7. Dimethyl acetamide (DMac) as a solvent (Merk, Germany).

8. Dibutyltin dilaurate (fluka, Switzerland).

9. Ammonia (Merk, Germany).

10. Asymmetric nano filter based membrane of polyester (plasmachemGmbH, Germany).

11. N-heptane (Romil, UK).

12. SPAN 80 (MERK, Germany).

13. Distilled water.

\section{Composite membrane preparation}

A certain amount of span 80 as surfactant, silicone propulsion (tetraethyl-ortho-silicate) with weight percentages of $8 \%$ with oligomers of polydimethylsiloxane and polyethylene glycol in $\mathrm{n}$-heptane (solvent) at room temperature for making homogeneous solution mixed together. Ammonia in water (anti-solvent) with half the molar concentration of the solution is solved to build a solution with $\mathrm{pH}$ 9. However, a certain amount of this solution is added into a homogeneous solution under difficult conditions of stirring. Mass ratio between solvent and polymer is about 3.5 and the mass ratio between the polymers used in this study is equal. The use of ammonia as catalyst cause agglomerate silica has been done at the interface of water/homogeneous solution. After mixing for $30 \mathrm{~min}$, a small amount of Dibutyltin dilaurate as bubble removing is added to this mixture. The mass ratio between the polymer, Dibutyltin dilaurate, Span 80 and the solution with $\mathrm{pH} 9$ is 10/0.1/0.3/1, respectively. After removing bubbles in homogeneous solution, the solution is laying the base layer and the film device is used. The solution to build a base film by deposition technique made by immersion; therefore, a $15 \%$ the mass of solution polyethersulfone and 3\% the mass of the Polyvinylpyrrolidone as filler in the dimethylacetamide solvent is made. This solution is built on the base of nano-filter asymmetric polyester, and after using the film immersed quickly in distilled water to remove residual dimethylacetamide. Membranes initially are placed in the open air for $24 \mathrm{~h}$ and then to complete the cross-linking process and evaporate the remaining solvent at the time of cross-linking $(0.5-2.5 \mathrm{~h})$ determined and at the time of cross-linking time $\left(65-85^{\circ} \mathrm{C}\right)$ placed inside an electric furnace. Finally, the membranes are washed with distilled water and placed between sheets of filter paper and dried. All membranes before used in the membrane module and the membrane performance be measured should be placed in a free of dust and dry environment.

Laboratory devices for research is shown in Fig. 1.

Feed tank (position 1) is containing about three liters of diesel with the total sulfur content of $6380 \mathrm{ppm}$. After using any appropriate membrane, the remaining diesel is poured inside the feed tank and the feed will be replaced with new diesel to experiment with new membrane. In position 2, the pump has been used that leads diesel with different flow rates and pressures set (5-9 times) into the membrane module (position 5). Membrane modules is manufactured from stainless steel and membranes used with active area of $2100 \mathrm{~cm}^{2}$. The pressure gauges represents (position 4 and 6) the diesel and backflow pressures, respectively. Needle valves are installed at 7 positions to control the backflow and a valve is inserted in position 3 for the input flow to the module. The membranes in the input feed to the modulus to be kept wet approximately $1 \mathrm{~h}$ before the start of each test to achieve steady state conditions. For each test approximately $3 \mathrm{~h}$ were taken and the operating temperature range is between 65 and $85^{\circ} \mathrm{C}$.

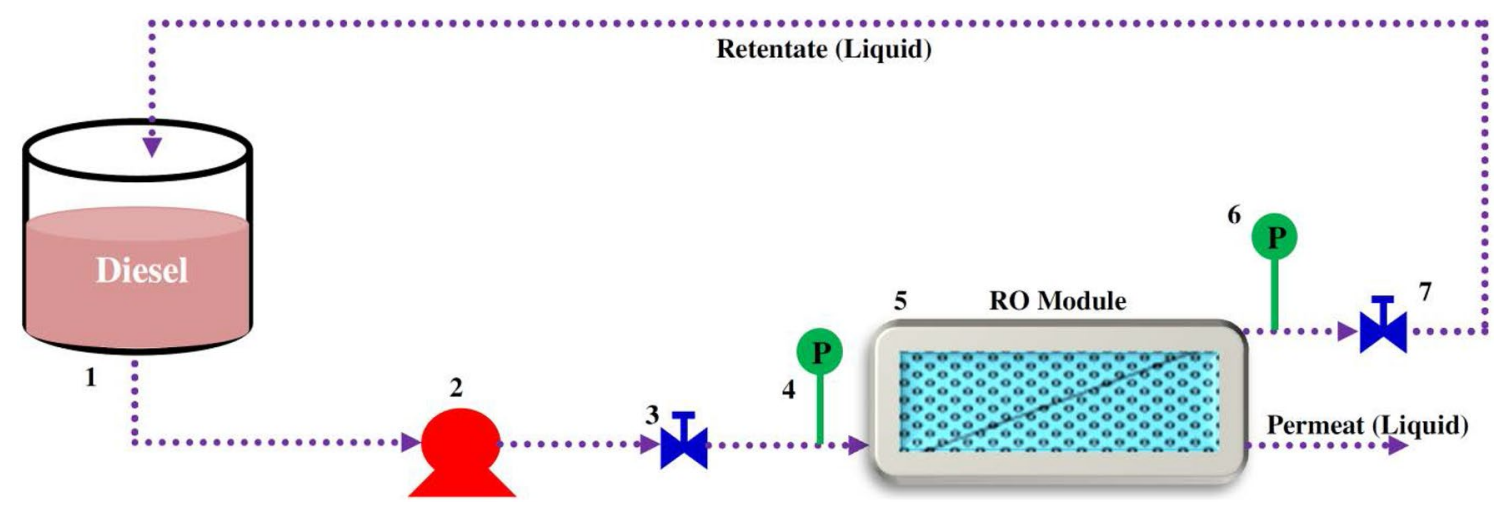

Fig. 1 Schematic diagram of experimental apparatus 


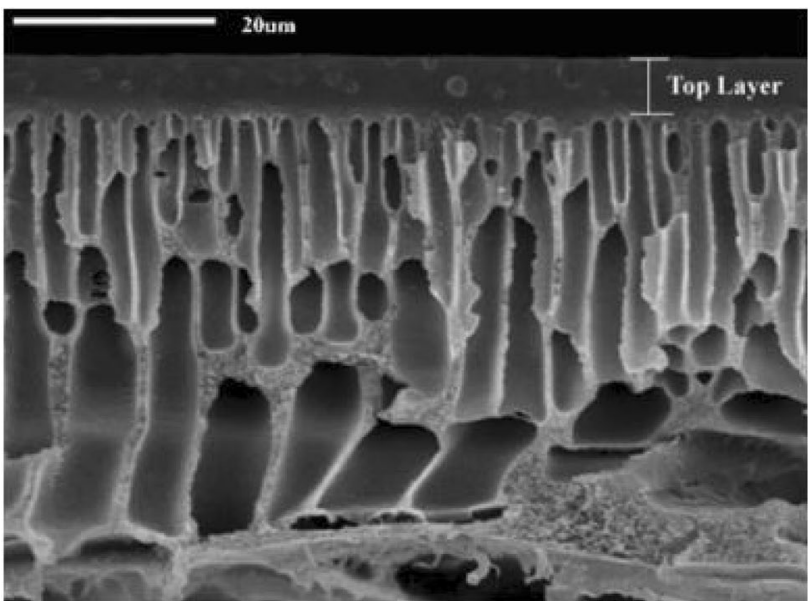

Fig. 2 The cross section morphology of the PDMS composite membrane

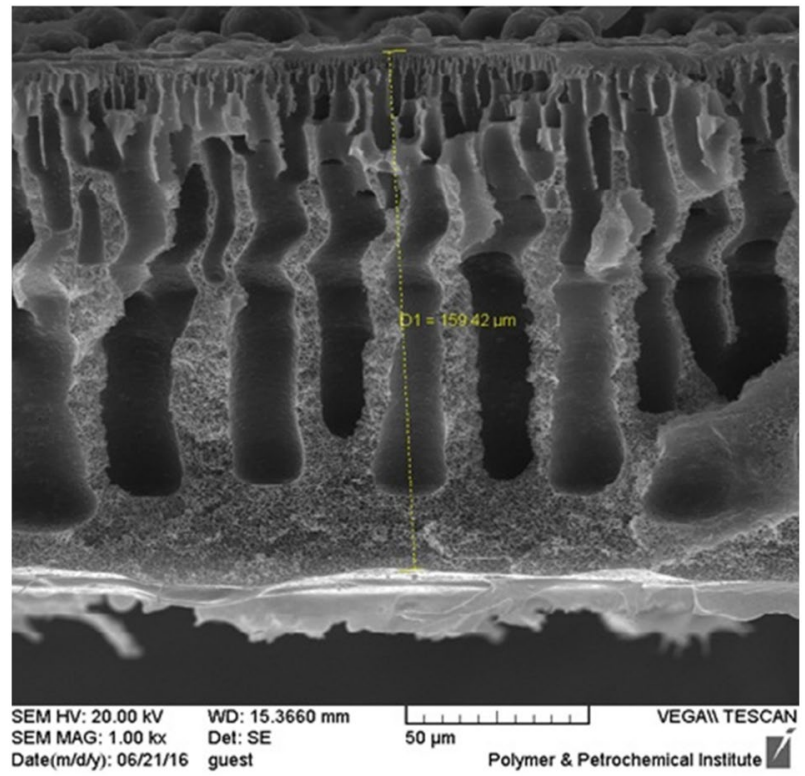

Fig. 3 Scanning electron microscope image of the composite membrane of PDMS

\section{Results and discussion}

Figures 2, 3, 4, 5 are scanning electron microscope images of PDMS composite membrane at a temperature of crosslinking $75{ }^{\circ} \mathrm{C}$ and cross-linking time of one hour and the amount of TEOS $8 \%$ by weight. These images show the porosity in internal layer of membrane. As demonstrated in the SEM photographs, there is a clear boundary between the PDMS top layer and support layer. Meanwhile, the cross-sectional structure of the composite membrane of

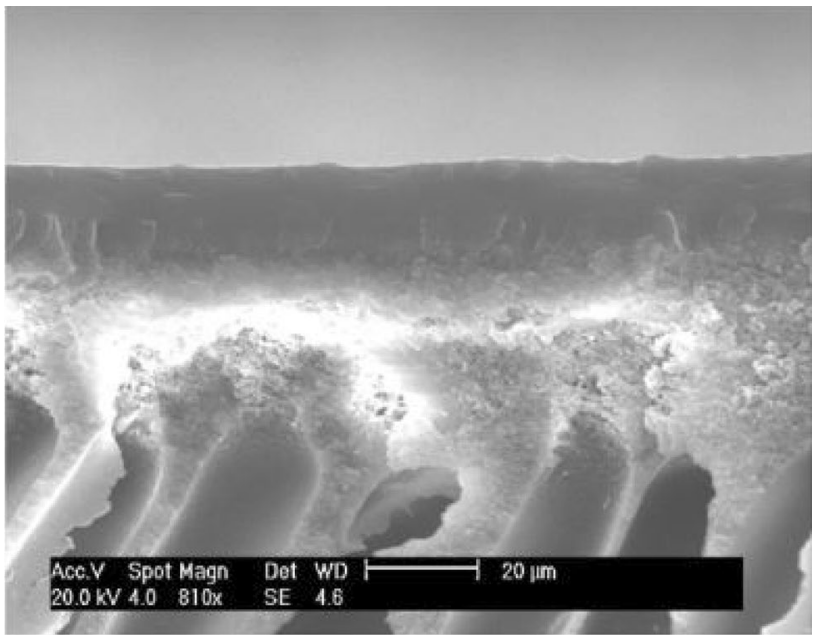

Fig. 4 SEM images of the cross-section of composite PDMS membrane

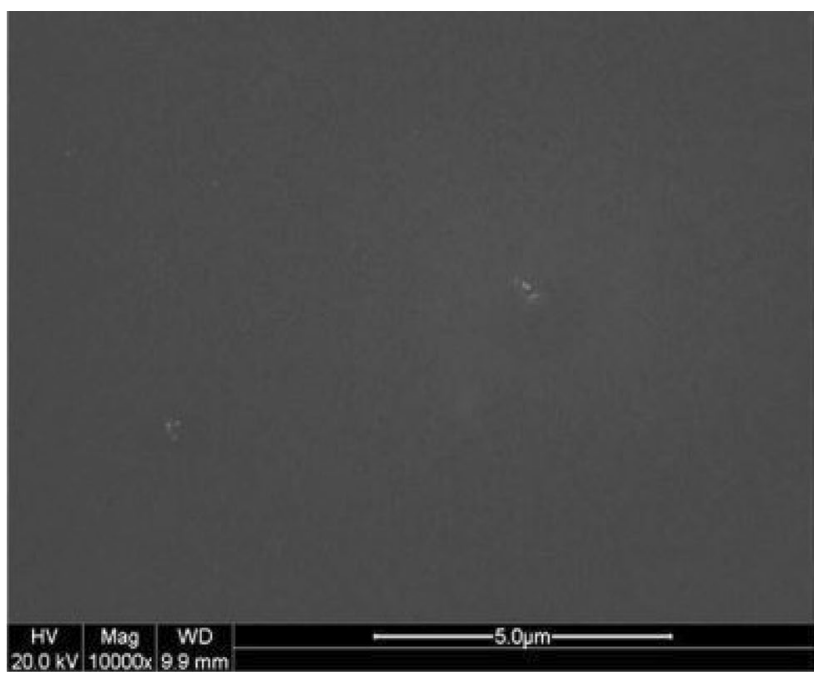

Fig. 5 The surface morphology of the PDMS composite membrane

PDMS with TEOS as agent, consisted of an ultrathin skin layer and a porous finger-like structure. The top dense layer is clearly demonstrated in Figs. 2 and 4. Using Soaking method, porosity of the membrane, $33.308 \%$, was obtained. Furthermore, the thickness of the PDMS top layer was determined to be about $4.5 \mu \mathrm{m}$ from the SEM photograph by the scale tab. Note that, top-layer thickness increased as the PDMS concentration increased. Also, the thickness of membrane support obtained as $130 \mu \mathrm{m}$.

The surface morphology of the composite membrane is shown in Fig. 5. From this figure, the originally porous surface was covered by a flat featureless PDMS layer, and the top PDMS layer, functioning as the basis of selectivity, had a nonporous and tight structure. The surface of the 
composite is dense and there is no pinhole or crack, which is important for practical application.

Figure 6 shows that the total flux changes with the use of TEOS as cross-linking agent in the manufacture of membranes, which in accordance with Fig. 6 with increasing consumption of TEOS output flux from retentate stream is reduced. This result implied that, when the TEOS content increased, more TEOS chains occurred in cross-linking reaction, and the top membrane layer, functioning as the basis of permselectivity, became a nonporous and very tight structure. Accordingly, the free volume of PDMS composite membrane decreased, which led to the flux decrease. Meanwhile, top-layer thickness increased as the TEOS concentration increased. By all given reasons, the flux decreased as TEOS content increased. According to Fig. 6, it can be seen that the highest flux is related to the blending polymers PDMS + PEG, which it uses the technique of blending polymers with the PDMS as a hydrophobic polymer and PEG as a hydrophilic polymer.

Figure 7 shows sulfur is reduced in the back flow with the use of TEOS as a cross-linking agent. According to Fig. 7, increasing the amount of TEOS in manufacturing composite membranes reduces the amount of sulfur in the return flow. Because by increasing the amount of TEOS as cross-linking agent, the selectivity of composite membrane increased and consequently total sulfur in retentate flow decreases.

Figure 8 shows sulfur changes in the back flow with cross-linking temperature that $8 \%$ weight of TEOS is used as cross-linking agent in the construction of composite membranes, which according to Fig. 8 increasing cross-linking temperature reduces total sulfur flux.

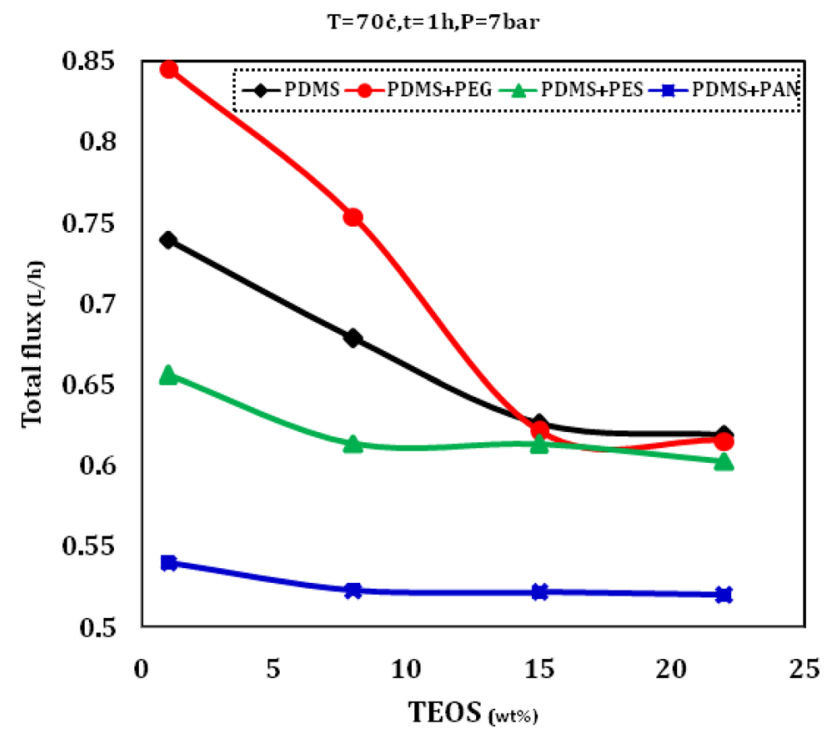

Fig. 6 Total flux changes with consuming value of mass percentage of crosslinking agent at $70{ }^{\circ} \mathrm{C}$ and crosslinking time of $1 \mathrm{~h}$ and membrane module pump pressure in 7 bar

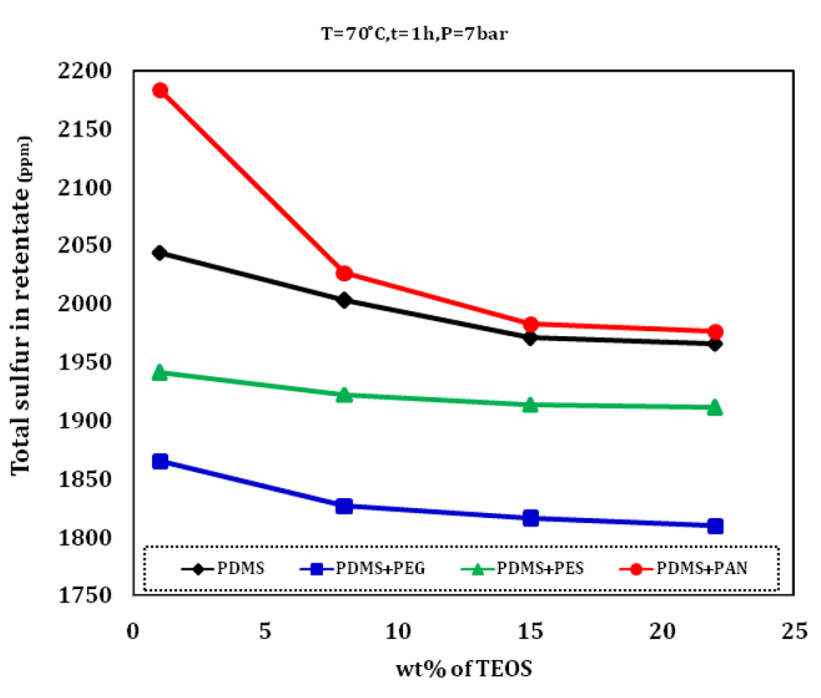

Fig. 7 Sulfur changes in the back flow using mass percentage of crosslinking agent, at $70^{\circ} \mathrm{C}$, crosslinking time of $1 \mathrm{~h}$ and membrane module pump pressure in 7 bar

As cross-linking temperature $\left(65-85^{\circ} \mathrm{C}\right)$ increases, the degree of equilibrium swelling decreases and thus the selectivity of the composite membrane increases. Some observations show reducing the chain length between the crosslinking. Reducing chains between cross-linking increases the elastic resistance of swelling stress in composite membranes and thus the swelling degree of the membrane reduces. Thereby, reducing the degree of swelling increases the selectivity of the composite membranes to sulfur compounds and ultimately the amount of sulfur in the backflow reduces.

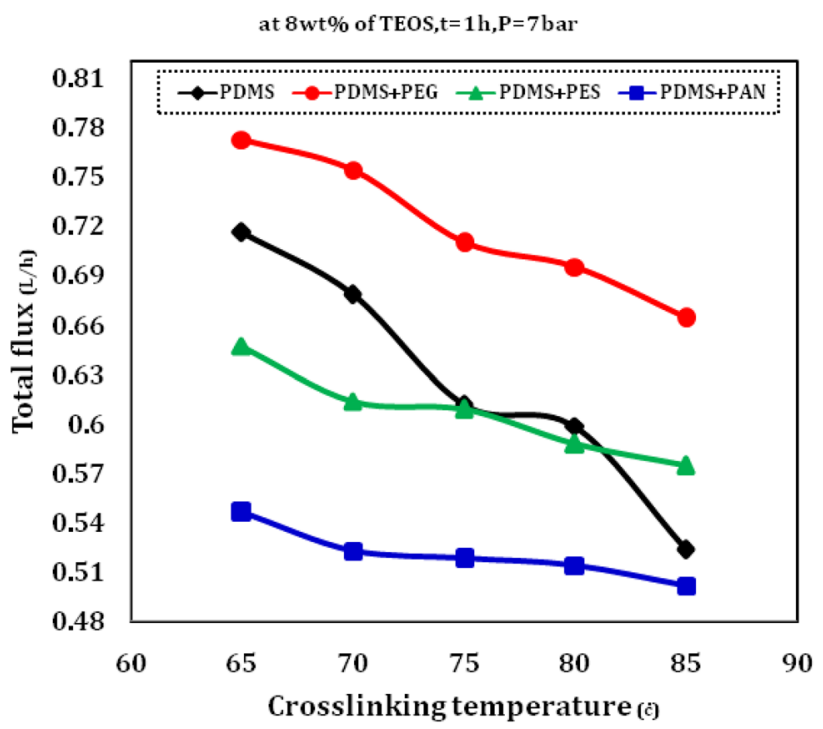

Fig. 8 Total flux changes with crosslinking temperature at $8 \%$ mass of the cross-linking agent and crosslinking time of $1 \mathrm{~h}$ and membrane module pump pressure in 7 bar 


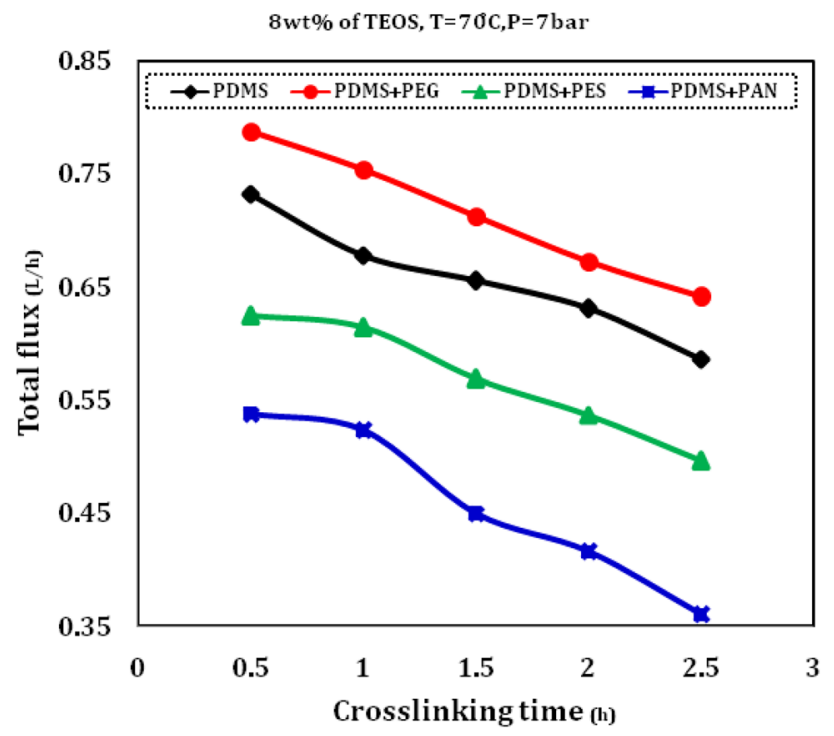

Fig. 9 Total flux changes with crosslinking time at $8 \%$ mass of crosslinking agent and crosslinking temperature of $70{ }^{\circ} \mathrm{C}$ and membrane module pump pressure in 7 bar

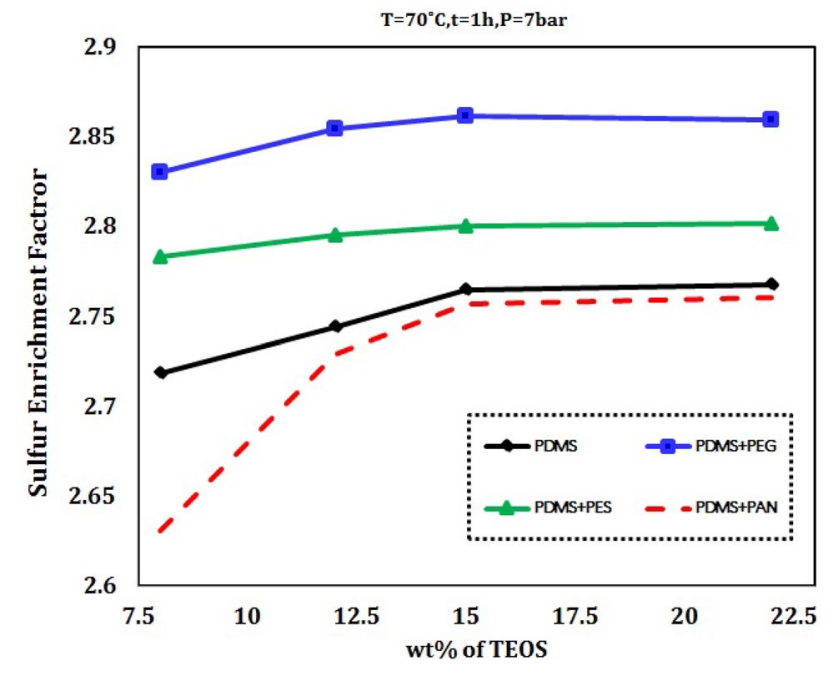

Fig. 10 Sulfur enrichment factor as a function of TEOS percentage

Figure 9 shows total flux changes with cross-linking time in the case of $8 \%$ weight TEOS as a cross-linking agent is used in the construction of composite membranes. According to Fig. 9, the total flux is reduced with increasing crosslinking time from 0.5 to $2.5 \mathrm{~h}$.

The effects of crosslinking dosage, crosslinking time and temperature are illustrated in Figs. 10, 11, 12. As can also be seen in these figures, the blended PDMS + PEG polymer shows a higher enrichment factor than other cases. In consequence to previous descriptions, when the total sulfur in retentate flow decreases so the enrichment factor will be increased. The sulfur enrichment factor is defined as the

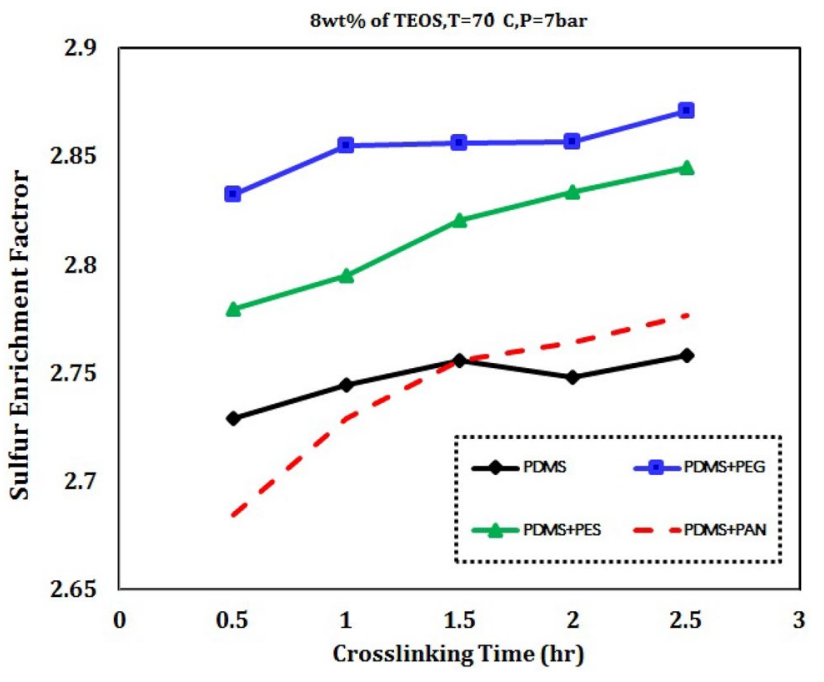

Fig. 11 Sulfur enrichment factor as a function of time

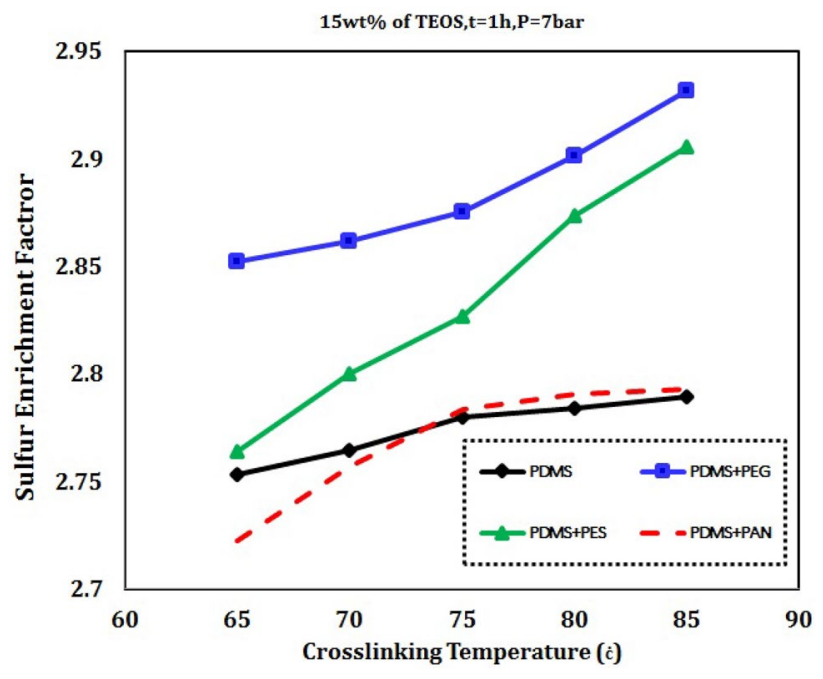

Fig. 12 Sulfur enrichment factor as a function of temperature

ratio of total sulfur content of permeate to total sulfur content of feed samples.

\section{Conclusion}

In this work, PDMS, PEG, PES and PAN composite membranes have been prepared to reduce sulfur diesel fuel using cross-linking technique by TEOS cross-linking agent in various mass percentages. According to results it can be seen that most of the total flux is related to composite membranes of PEG + PDMS $(0.7732 \mathrm{~L} / \mathrm{h})$. In addition, it is observed that the lowest amount of sulfur in the back flow related to the state in which the composite membranes PEG + PDMS had been used (1780 ppm). Increasing use of TEOS reduces the 
total flux passing retentate stream, however, the amount of sulfur in the return flow is also reduced. It can be noted that by increasing the amount of TEOS from 8 to $22 \mathrm{wt} \%$. in the case of composite membranes PDMS + PAN, PDMS + PES, PDMS + PEG, PDMS, the flux changed from 0.5412 to $0.5217 \mathrm{~L} / \mathrm{h}, 0.6215$ to $0.6033 \mathrm{~L} / \mathrm{h}, 0.7583$ to $0.6211 \mathrm{~L} / \mathrm{h}$ and 0.6813 to $0.6314 \mathrm{~L} / \mathrm{h}$, respectively; while, the differences between the total flux passing through the composite membranes are too much in the range of $1-8 \mathrm{wt} \%$ relative to $15-22 \mathrm{wt} \%$. Also by increasing use of TEOS from $8 \%$ to $22 \mathrm{wt} \%$ in the case of composite membranes PDMS + PAN, PDMS + PES, PDMS + PEG, PDMS, the amount of sulfur in the back flow is changed from 2035 to $1982 \mathrm{ppm}, 1933$ to $1921 \mathrm{ppm}, 1825$ to $1811 \mathrm{ppm}, 2011$ to $1972 \mathrm{ppm}$, respectively; while, the differences between the amount of sulfur in the back flow is too much in the range of $1-8 \mathrm{wt} \%$ relative to $15-22 \mathrm{wt} \%$.

Acknowledgement The authors gratefully acknowledge the scientific institutes and companies that they sincerely helped to this research. Among them can be mentioned the following: 1-Esfahan Oil Refining Company, 2-Iran Polymer and Petrochemical Institute (IPPI), 3-Chemistry \& Chemical Engineering Research Center of Iran (CCERCI), 4-Razi University.

Open Access This article is distributed under the terms of the Creative Commons Attribution 4.0 International License (http://creativeco mmons.org/licenses/by/4.0/), which permits unrestricted use, distribution, and reproduction in any medium, provided you give appropriate credit to the original author(s) and the source, provide a link to the Creative Commons license, and indicate if changes were made.

\section{References}

1. Lin L, Kong Y, Xie K (2008) Polyethylene glycol/polyurethane blend membranes for gasoline desulphurization by pervaporation technique. Sep Purif Technol. https://doi.org/10.1016/j.seppu r.2007.10.020

2. Lin L, Kong Y, Zhang Y (2008) Poly ethylene glycol/polyurethane blend membranes for gasoline desulphurization by pervaporation technique. J Member Sci. https://doi.org/10.1016/j.memsc i.2008.08.019

3. Wu H, Zhang X, Xu D, Li B, Jiang Z (2009) Enhancing the interfacial stability and solvent-resistant property of PDMS/PES composite membrane by introducing a bifunctional aminosilane. J Membr Sci. https://doi.org/10.1016/j.memsci.2009.03.043

4. Xu R, Liu G, Dong X, Jin W (2010) Pervaporation separation of n-octane/thiophene mixtures using poly dimethyl siloxane/ceramic composite membranes. Desalination. https://doi.org/10.1016/j. desal.2010.03.035

5. Lin L, Zhang Y, Li H (2010) Pervaporation and sorption behavior of zeolite filled polyethylene glycol hybrid membranes for the removal of thiophene species. J Colloid Interface Sci. https://doi. org/10.1016/j.jcis.2010.06.031

6. Reza Kazemi M, Shahidi K, Mohammadi T (2012) Hydrogen separation and purification using crosslinkable PDMS/zeolite A nanoparticles mixed matrix membranes. Inter J Hyd Energy. https ://doi.org/10.1016/j.ijhydene.2012.06.104

7. Reza Kazemi M, Shahidi K, Mohammadi T (2015) Synthetic PDMS composite membranes for pervaporation dehydration of ethanol. Desal Water Treat. https://doi.org/10.1080/19443 994.2014.887036

8. Chen J, Li J, Qi R, Ye H, Chen C (2010) Pervaporation separation of thiophene-heptane mixtures with poly dimethyl siloxane (PDMS) membrane for desulfurization. App Biochem Biotech. https://doi.org/10.1007/s12010-008-8368-z

9. Rostamizadeh AM, Reza Kazemi M, Shahidi K, Mohammadi T (2013) Gas permeation through $\mathrm{H} 2$-selective mixed matrix membranes: experimental and neural network modeling. Inter J Hyd Energy. https://doi.org/10.1016/j.ijhydene.2012.10.069

10. Reza Kazemi M, Mohammadi T (2013) Gas sorption in H2-selective mixed matrix membranes: Experimental and neural network modeling. Inter J Hydro Energy. https://doi.org/10.1016/j.ijhyd ene.2013.08.062

11. Reza Kazemi M, Vatani A, Mohammadi T (2016) Synthesis and gas transport properties of crosslinked poly(dimethylsiloxane) nanocomposite membranes using octatrimethylsiloxy POSS nanoparticles. J Nat Gas Sci Eng. https://doi.org/10.1016/j.jngse .2016 .01 .033

12. Reza Kazemi M, Vatani A, Mohammadi T (2015) Synergistic interactions between POSS and fumed silica and their effect on the properties of crosslinked PDMS nanocomposite membranes. RSC Adv. https://doi.org/10.1039/C5RA13609A

13. Rajesha BJ, Halali V, Geetha R, Padakia M, Nazri NAM (2017) Effective composite membranes of cellulose acetate for removal of benzophenone-3. J Water Proc Eng. https://doi.org/10.1016/j. jwpe.2017.06.003

14. Ghasemian S, Sahari M, Ali Barzegar M, Ahmadi G (2017) Omega-3 PUFA concentration by a novel PVDF nano-composite membrane filled with nano-porous silica particles. Food Chem. https://doi.org/10.1016/j.foodchem.2017.02.135

15. Xu Z, Li X, Teng K, Zhou B, Ma M, Shan M, Jiao K, Qian X, Fan J (2017) High flux and rejection of hierarchical composite membranes based on carbon nanotube network and ultrathin electrospun nanofibrous layer for dye removal. J Mem Sci. https://doi. org/10.1016/j.memsci.2017.04.029

Publisher's Note Springer Nature remains neutral with regard to jurisdictional claims in published maps and institutional affiliations. 